\title{
Performance Evaluation Method and Algorithm of Knowledge Management for Product Innovation Design
}

\author{
http://dx.doi.org/10.3991/ijoe.v9iS2.2604 \\ Yongdang Chen, Huijuan Ren, Zhiqiang Bao, Guangmei Liu and Huali Ma \\ Xi'an Polytechnic University, Xi'an, China
}

\begin{abstract}
This paper presents a discussion of knowledge management performance evaluation index and evaluation methods for product innovation. The content of knowledge management and the flow of knowledge in product innovation process are analyzed. According to the purpose of performance evaluation and combined with the characteristics of product innovation, the knowledge management performance index for product innovation is established, and the specific evaluation method and algorithm are described. The fuzzy comprehensive evaluation process is discussed.
\end{abstract}

Index Terms-product innovation, knowledge management, performance evaluation

\section{INTRODUCTION}

With the life cycles of modern product design are getting shorter and the customer's growing demand for personalized, product innovation has become an important strategic choice for the enterprise to win a long-term development in the fierce market competition [1-3]. Knowledge management for product innovation process enriched the business management content. Internal the same innovation projects and between different product innovation projects, knowledge management emphasizes the sharing of knowledge within the project and cooperation between different projects $[4,5]$. Knowledge management plays an important role for product innovation process. It affects the efficiency of product innovation and the results. Therefore, it is particularly important to evaluate how important the knowledge management promotes the process of product innovation. Through evaluate the performance of knowledge management for product innovation, it provides a basis for the enterprise to develop a scientific and rational knowledge management strategy. Thus improve the efficiency of product innovation process and accumulate experience for the next phase of product innovation process [6,7]. This paper established the product innovation performance index based on the purpose of the performance evaluation and the characteristics of product innovation. This can provide some reference for relevant research and provide a theoretical reference for enterprises to improve product innovation capability.

\section{KNOWLEDGE CONTENT AND FLOW In PRODUCT INNOVATION}

There are many ways for innovation, but they all need a lot of existing knowledge and experience to support. Specifically, it includes scientific principles, technical knowledge, social knowledge, experience, success cases and even failures, and so on [8,9]. It is a source of innovation. Knowledge is the main raw material for product innovation.

Product innovation is a process of knowledge creation, development, transfer and application. It's also a cycle process of continuous improvement. Knowledge generation is a process of new knowledge discovery and created. Knowledge developments reprocess the knowledge which the enterprise already have or get. Its makes the existing knowledge standardized and explicit that makes people easy to identify and understand. Knowledge transfer can make other people use knowledge more effectively by the publications and electronic publications. It also can transfer through education and training activities and personal teach that makes the knowledge to be more widely used. The application of knowledge is a process of make the knowledge meet the customers' needs. This process transforms the knowledge into new products or services by product innovation. Customers enjoy using the product or service and feedback the information include the evaluation of the product and their recommended and customer's experience. And the developer based on feedback combined with new market demands start the next stage of product development. And this process will be repeated circular. The process of knowledge flows as figure 1.

The division of stage of the product innovation process is consistent with the knowledge flow process. Different stage of product innovation process is corresponding with specific knowledge flow process. The concept design stage produces the "original knowledge" based on demand and product application requirements. Production planning stage and detailed design stage application knowledge to production process and providing product. Mass-production/ selling stage transfer the knowledge into product to meet customer's demand. Compared with the product innovation process, the knowledge flow stage set aside a specific form of product innovation and enable enterprises more accurately grasp the law of knowledge flow in the product innovation process. 
SPECIAL FOCUS PAPER

Performance Evaluation Method and Algorithm of Knowledge Management for Product Innovation Design

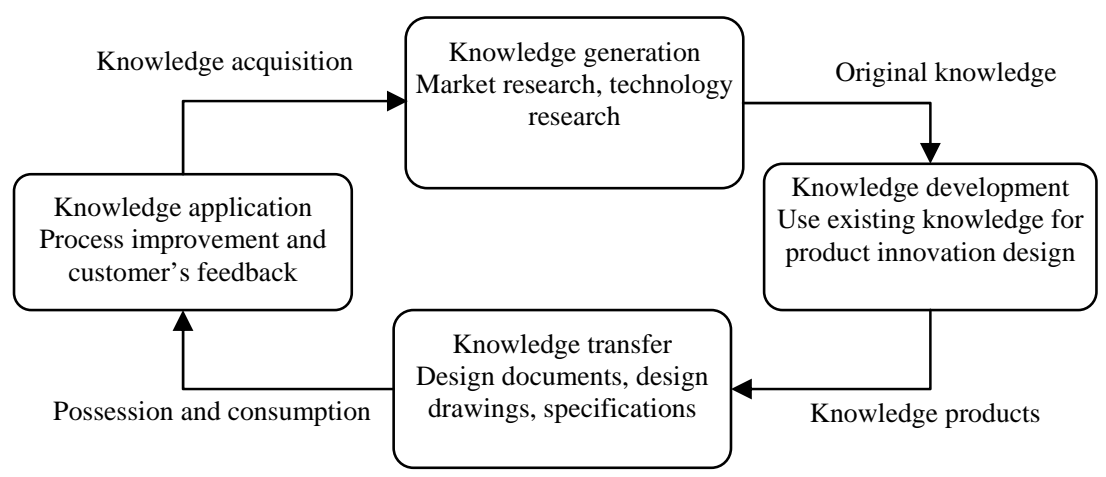

Figure 1. Knowledge flow in product innovation process

\section{Knowledge Management Performance EVALUATION INDEX}

According to the purpose and principles of performance evaluation and reference relevant research on knowledge management performance evaluation at home and abroad, The paper sorted out knowledge management performance index for product innovation. This index including knowledge capital, knowledge innovation capital, technology capital, market capital, economic efficiency, competitive position 6 indicators and 18 secondary indicators, such as shown in table 1 .

Product innovation and development must need a lot of existing knowledge and experience support. It will also create new knowledge when application knowledge in the product development process. The utilization rate of existing knowledge and the knowledge exchange rate in product development has important implications for product innovation success. Therefore, through knowledge management, knowledge innovation capability improves as one aspect in the product development process is needed to evaluate. And knowledge capital must be considered in the enterprise knowledge management performance evaluation process.

Product innovation approach is varied. Product innovation is the process of integrate internal and external resources and cooperate with different departments to use the existing knowledge. It improves the innovative capability by continuous learning and using the knowledge. The evaluation of this indicator include three aspect as increase rate of the number of cooperative projects with research institutions, co-operation project success rate, developers capacity of utilization and learning knowledge increase to reflect the knowledge management performance for product innovation.

TABLE I. KNOWLEDGE MANAGEMENT PERFORMANCE EVALUATION INDEX

\begin{tabular}{|c|c|c|}
\hline \multirow{18}{*}{$\begin{array}{l}\text { Knowledge } \\
\text { management } \\
\text { performance } \\
\text { evaluation index for } \\
\text { product innovation }\end{array}$} & \multirow{3}{*}{ knowledge capital S1 } & Increase rate of the knowledge resources K1 \\
\hline & & Utilization rate of inventory knowledge $\mathrm{K} 2$ \\
\hline & & The frequency of knowledge exchange improve K3 \\
\hline & \multirow{3}{*}{$\begin{array}{l}\text { knowledge innovation } \\
\text { capital S2 }\end{array}$} & $\begin{array}{l}\text { Increase rate of the number of cooperative projects with research } \\
\text { institutions K4 }\end{array}$ \\
\hline & & Co-operation project success rate $\mathrm{K} 5$ \\
\hline & & $\begin{array}{l}\text { Developers capacity of utilization and learning knowledge } \\
\text { increaseK6 }\end{array}$ \\
\hline & \multirow{3}{*}{ technology capital S3 } & R\&D speed and number increase $\mathrm{K} 7$ \\
\hline & & $\mathrm{R} \& \mathrm{D}$ success rateK8 \\
\hline & & Increase rate of the number of patent applications K9 \\
\hline & \multirow{3}{*}{ market capital S4 } & Market share K10 \\
\hline & & Consumers' confidence on brand K11 \\
\hline & & Sales increase rate $\mathrm{K} 12$ \\
\hline & \multirow{3}{*}{$\begin{array}{l}\text { economic efficiency, } \\
\text { S5 }\end{array}$} & Sales profit increase rate $\mathrm{K} 13$ \\
\hline & & Total assets of remuneration increase rate K14 \\
\hline & & Percentage of innovative product revenue of total revenue K15 \\
\hline & \multirow{3}{*}{$\begin{array}{l}\text { competitive position } \\
\text { S6 }\end{array}$} & Enterprise image improve degrees K16 \\
\hline & & Enterprise market reputation K17 \\
\hline & & Sustainable development level K18 \\
\hline
\end{tabular}


Technology capital include three indicator as R\&D speed and number increase ,R\&D success rate, increase rate of the number of patent applications. Technology and knowledge are closely related and knowledge largely based on technical as their form of expression. The nature of technology capital is the integration knowledge and information that owned by the enterprise to support product innovation. This knowledge which attached to the developers and the organization itself reflected through product innovation process. And based on this process, the paper chose three secondary indicators reflect the technological capital level.

Market capital is the potential of market-related intangible assets owned by enterprise. Finally, the product of the product innovation development must selling on the market, market capitalization has become an important aspect of knowledge management performance evaluation. It is includes a variety of brands, customers and their trust, Sales increase rate, market share, Supply and sales business relationship, strategic alliances, customer satisfaction, customer relationship and other factors. The secondary indicators include three indicators as market share, consumers' confidence on brand, sales increase rate.

The ultimate purpose of knowledge management for product innovation process is to realize the economic benefit of enterprise growth .So the evaluation of economic indicators is essential in this index. The paper chose sales profit increase rate, total assets of remuneration increase rate, percentage of innovative product revenue of total revenue to evaluate the knowledge management performance for product innovation.

The core competitiveness of the enterprise finally reflected in profitability, market share, enterprise image and public recognition of enterprise products and services and so on. Different enterprise displays different enterprise competitive characteristics which is also the unique performance of the core competitiveness of the enterprise

\section{Performance Evaluations Method And ALGORITHM}

Some of the indicators of knowledge management performance evaluation index for product innovation are constructed in this paper. And the diversity and ambiguity feature indicate that the fuzzy comprehensive evaluation method is the best option. So we can use AHP (Analytical Hierarchy Process, AHP) to determine the weight of each indicator, and the fuzzy comprehensive evaluation method for comprehensive evaluation.

Here, an enterprise sample is used for the application study of the above method of performance evaluation. Main business of the enterprise is development of electronic components, design and production. It is an enterprise of high level technology, management science, and developed a knowledge management strategy. It is suitable for empirical research.

Five experts are invited to evaluate score for the index system. These experts involved in business managers, research personnel, and independently evaluated score with management experience and understanding.

Total evaluation index is as shown in table 2 . Secondary evaluation index is as shown in table 3.

TABLE II. TOTAL EVALUATION INDEX AND ANALYSIS CALCULATION

\begin{tabular}{l|cccccc|c|c}
\hline & $\mathrm{S} 1$ & $\mathrm{~S} 2$ & $\mathrm{~S} 3$ & $\mathrm{~S} 4$ & $\mathrm{~S} 5$ & $\mathrm{~S} 6$ & $W_{i}^{0}$ & \\
\hline S1 & 1 & $1 / 2$ & $1 / 3$ & $1 / 4$ & $1 / 5$ & $1 / 3$ & 0.053 & \\
S2 & 2 & 1 & 2 & 1 & $1 / 3$ & 1 & 0.148 & \\
S3 & 3 & $1 / 2$ & 1 & 1 & $1 / 3$ & 2 & 0.141 & $\lambda_{\max } \approx 6.318$ \\
S4 & 4 & 1 & 1 & 1 & $1 / 3$ & $1 / 2$ & 0.133 & C.I. $=0.064<0.1$ \\
S5 & 5 & 3 & 3 & 3 & 1 & 3 & 0.384 & \\
S6 & 3 & 1 & $1 / 2$ & 2 & $1 / 3$ & 1 & 0.141 & \\
\hline
\end{tabular}

TABLE III. SECONDARY EVALUATION INDEX AND ANALYSIS CALCULATION

\begin{tabular}{|c|c|c|c|c|c|c|c|c|c|c|c|}
\hline $\mathrm{S} 1$ & K1 & K2 & K3 & $W_{i}^{0}$ & & $\mathrm{~S} 2$ & K4 & K5 & K6 & $W_{i}^{0}$ & \\
\hline K1 & 1 & $1 / 3$ & $1 / 5$ & 0.105 & $\lambda_{\max } \approx 3.038$ & K4 & 1 & $1 / 5$ & $1 / 3$ & 0.105 & $\lambda_{\max } \approx 3.038$ \\
\hline K2 & 3 & 1 & $1 / 3$ & 0.258 & C.I. $=0.019<0.1$ & K5 & 5 & 1 & 3 & 0.637 & C.I. $=0.019<0.1$ \\
\hline K3 & 5 & 3 & 1 & 0.637 & & K6 & 3 & $1 / 3$ & 1 & 0.258 & \\
\hline S3 & K7 & K8 & K9 & $W_{i}^{0}$ & & S4 & K10 & K11 & K12 & $W_{i}^{0}$ & \\
\hline K7 & 1 & $1 / 2$ & 2 & 0.297 & & K10 & 1 & 2 & $1 / 5$ & 0.187 & \\
\hline K8 & 2 & 1 & 3 & 0.540 & $\begin{array}{c}\lambda_{\max } \approx 3.009 \\
\text { C.I. }=0.005<0.1\end{array}$ & K11 & $1 / 2$ & 1 & $1 / 4$ & 0.127 & $\begin{array}{c}\lambda_{\max } \approx 3.094 \\
\text { C.I. }=0.046<0.1\end{array}$ \\
\hline K9 & $1 / 2$ & $1 / 3$ & 1 & 0.163 & & $\mathrm{~K} 12$ & 5 & 4 & 1 & 0.686 & \\
\hline S5 & K13 & K14 & K15 & $w_{i}^{0}$ & & S6 & K16 & K17 & K18 & $W_{i}^{0}$ & \\
\hline K13 & 1 & 5 & 3 & 0.637 & & K16 & 1 & $1 / 3$ & 1 & 0.21 & \\
\hline K14 & $1 / 5$ & 1 & $1 / 3$ & 0.105 & $\begin{array}{c}\lambda_{\max } \approx 3.039 \\
\text { C.I. }=0.019<0.1\end{array}$ & K17 & 3 & 1 & 2 & 0.55 & $\begin{array}{c}\lambda_{\max } \approx 3.018 \\
\text { C.I. }=0.009<0.1\end{array}$ \\
\hline K15 & $1 / 3$ & 3 & 1 & 0.258 & & K18 & 1 & $1 / 2$ & 1 & 0.24 & \\
\hline
\end{tabular}


We use fuzzy comprehensive evaluation method for knowledge management performance evaluation and the steps as follows:

1) Determining the evaluation index and divided these into s subsets and noted as: $U_{1}, U_{2}, \cdots, U_{s}$, and satisfy the conditions:

$$
U=\left\{U_{1}, U_{2}, \ldots, U_{\mathrm{s}}\right\} \quad, \quad U_{i} \cap U_{j}=\Phi(i \bullet j) \quad, \quad \text { and }
$$
$U_{i}=\left\{U_{i 1}, U_{i 2}, \ldots, U_{\text {in }}\right\}, i=1,2, \cdots, s, n$ is the number of elements of $U_{i}$ 。 Here, $s=6, n=3$.

2) Make all the reviews set of the evaluation indicators: $Y=\left\{\begin{array}{lll}Y_{1} & Y_{2}, \ldots, Y_{m}\end{array}\right.$.

3) Take single-index evaluation for each evaluation indicators and draw the index evaluation matrix: $R_{i}=\left(r_{i j k}\right)_{n i+m}$ where $i=1,2, \cdots, \mathrm{s} ; j=1,2, \cdots, \mathrm{n}_{\mathrm{i}} ; k=1,2, \cdots$, $\mathrm{m}$. And $r_{i j k}$ means the degree of subordinate of $X_{i j}$ under reviews of $Y_{k}$. We use expert evaluation method for comprehensive evaluation and according to the actual significance determine the indicators evaluate matrix $R_{i}$. Detailed process is: Each expert give number grade for each of the indicators $X_{i j}$ based on the reviews and the grade range in [0-1].And last: $\sum_{k=1}^{m} Y_{k}=1$. After score for each indicator in each of the reviews, calculate the average score as the final score. And this score is the degree of subordinate of on correspond reviews.

4) Give each indicator weight: $W_{I}=\left\{a_{i 1}, a_{i 2}, \ldots, a_{i m}\right\}$, where: $\sum_{j=1}^{n_{i}} a_{i j}=1$

5) The final reviews are : $B_{i}=W_{i} \bullet R_{i}=\left\{b_{i 1}, b_{i 2}, \ldots, b_{i m}\right\}$, $i=1,2, \cdots, \mathrm{s}$.

6) Regard $U_{i}$ as a separate element and $\mathrm{Bi}$ as the evaluation vector of $U_{i}$, that could form the fuzzy evaluation matrix $R$ of $U$ to $V$ :

$$
B_{i}=\left(\begin{array}{c}
B_{1} \\
B_{2} \\
\cdot \\
\cdot \\
\cdot \\
B_{j}
\end{array}\right)=\left(\begin{array}{lllllll}
b_{11} & , & b_{12} & , & \ldots & , & b_{1 m} \\
b_{21} & , & b_{22} & , & \ldots & , & b_{2 m} \\
\ldots & & & & \\
\ldots & & & \\
\ldots & & & \\
b_{j} 1 & , & b_{j 2} & , & \ldots & , & b_{j m}
\end{array}\right)=\left\{\begin{array}{ccccc}
0.064 & 0.126 & 0.279 & 0.411 & 0.121 \\
0.011 & 0.074 & 0.364 & 0.362 & 0.190 \\
0 & 0.046 & 0.162 & 0.438 & 0.354 \\
0.081 & 0.019 & 0.350 & 0.350 & 0.200 \\
0 & 0.085 & 0.491 & 0.273 & 0.152 \\
0.055 & 0.100 & 0.355 & 0.369 & 0.121
\end{array}\right\}
$$

According to weight of importance of $U_{i}$ in $U$, $w=\left\{a_{1}, a_{2}, \ldots, a_{\mathrm{i}}\right\}$, calculate the final reviews vector: $B=W \bullet R=\left(b_{1}, b_{2}, \ldots, b_{m}\right)$

7) Calculate the final score: G=BVT.

$$
G=\left[\begin{array}{lllll}
0.023 & 0.073 & 0.377 & 0.340 & 0.186
\end{array}\right] \bullet\left[\begin{array}{c}
-5 \\
-3 \\
1 \\
3 \\
5
\end{array}\right]=1.992
$$

According to the result, knowledge management performance of the enterprise is between general and good. The result is match with actual situation of the enterprise.

\section{CONCLUSIONS}

Knowledge has become an important factor of production. Implementation knowledge management is an important strategic choice for enterprises gain a competitive advantage in the fierce market competition. Knowledge management performance evaluation for product Innovative have great significance for enterprise to develop innovative policies and product innovation strategic objectives. It also helps the enterprise improve its ability of product innovation and the level of innovation management. This study of knowledge management performance evaluation for product innovation designed to provide a reference for the relevant research and provide a theoretical reference for enterprises to improve product innovation capability.

\section{REFERENCES}

[1] Mylnikov. L.A., "A system view of the problem of the modeling and control of production innovations.” Sci. Tech. Info. Proce., vol. 39, no. 2, pp. 93-106, 2012. http://dx.doi.org/10.3103/ S0147688212020098

[2] T. Kevin C., E. Waleed, “An intelligent system based on concurrent engineering for innovative product design at the conceptual design stage.” Int. J. Adv. Manu. Tech., vol. 63, no. 5, pp. 421-447, 2012. http://dx.doi.org/10.1007/s00170-012-3932-7

[3] G. Ian, A. Abu Khari Bin, "The development of an online support tool for the teaching and learning of the IEEE standard 1500 for embedded core-based integrated circuits." Int. J. Online Eng., vol. 8, no. 4, pp. 42-49, 2012.

[4] C. Su, Y. Chen, S. David, "Managing product and customer knowledge in innovative new product development.” Int. J. Tech. Manag., vol. 39, no. 1, pp. 105-130, 2007. http://dx.doi.org/10.1504/IJTM.2007.013443

[5] M. Marjan, A. Shamsuddin, D. Siti Zawiah Md et al., “A framework for sharing knowledge in product development by Ecollaboration through project management.” Res. J. Appl. Sci. Eng. Technol., vol. 4, no. 6, pp. 649-659, 2012.

[6] C. Kathryn, O. David, “A collaborative knowledge management tool for product innovation management.” Int. J. Tech. Manag., vol. 26, no. 1, pp. 53-67, 2003. http://dx.doi.org/10.1504/IJTM. 2003.003144

[7] N. Somchai, I. Barbara, "Managing knowledge in new product and service development: A new management approach for innovative research organizations.” Int. J. Tech. Manag., vol. 28, no. 7, pp. 667-684, 2004. http://dx.doi.org/10.1504/IJTM. 2004.005776

[8] G. Kamal, N. Abdollah, "The effect of country of origin on purchase intention: The role of product knowledge.” Res. J. Appl. Sci. Eng. Technol., vol. 4, no. 9, pp. 1166-1171, 2012.

[9] S. Ravi, M. Neha, R. Samuel, B. Alok, A. Sourish, "A collaborative framework to minimise knowledge loss in new product development.” Int. J. Prod. Res., vol. 51, no. 7, pp. 20492059, 2013. http://dx.doi.org/10.1080/00207543.2012.701779

\section{AUTHORS}

Yongdang Chen is with College of Mechanical \& Electrical Engineering, Xi'an Polytechnic University, Xi’an, 710048 China (e-mail: chenyongd@163.com).

Huijuan Ren is with College of Computer Science, Xi’an Polytechnic University, Xi'an, 710048 China (email: renhuij@126.com).

Zhiqiang Bao is with College of Mechanical \& Electrical Engineering, Xi'an Polytechnic University, Xi'an, 710048 China (e-mail: baozhiqiang214@qq.com).

Guangmei Liu is with College of Mechanical \& Electrical Engineering, Xi'an Polytechnic University, Xi'an, 710048 China (e-mail: 937850450@qq.com).

Huali Ma is with College of Mechanical \& Electrical Engineering, Xi'an Polytechnic University, Xi'an, 710048 China (e-mail: 690507282@qq.com).

This work was supported by Science \& Technology Research Guidance Program Funded by China National Textile And Apparel Council (No.2011087), the Scientific Research Program Funded by Shaanxi Provincial Education Department (No.11JK1034), and Science \& Technology Research Program in Xi'an City (Program No.CXY1125-1). It is an extended and modified version of a paper presented at the International Conference on Mechanical Engineering, Automation and Material Science (MEAMS2012), held 22-23 December 2012, Wuhan, China. Received 14 February 2013. Published as resubmitted by the authors 25 March 2013. 